\title{
Medical treatment of ulcerative colitis: scoring the advances
}

There is no doubt that the outlook for the patient with ulcerative colitis is better than it was 50 years ago when sulphasalazine was first introduced. ${ }^{1}$ Much of the decreased mortality can be attributed to corticosteroids first shown to be effective in ulcerative colitis in 1952. The next milestone was widespread prescription of sulphasalazine, once it had been clearly established that it prolongs remission. ${ }^{34}$ In the following 25 years much has happened, but have there been major therapeutic advances?

\section{Oral treatments}

\section{SA L ICY LATES}

The demonstration that 5 amino salicylic acid (mesalazine) could induce remission in more patients with active disease than sulphapyridine ${ }^{s}$ is rightly regarded as seminal and has been supported by subsequent evidence of activity for maintenance of remission. ${ }^{6-12}$ It is worth remembering that these studies did not prove that unsplit sulphasalazine had no intrinsic activity (nor, incidentally, that sulphapyridine was devoid of therapeutic activity, though the latter seems likely).

The major advance which such data imply has not yet occurred. If sulphasalazine acts solely through 5 amino salicylic acid it should be possible to develop drugs capable of delivering much greater amounts to the colon without sulphapyridine related side effects. Alternatives to sulphasalazine in which sulphapyridine has been eliminated have, of course, been developed. Those at the most advanced stage illustrate the two main approaches that have been adopted. Polymer coated mesalazine (marketed as Asacol in the United Kingdom) uses the principle of delaying release, in order to avoid small intestinal absorption until the drug reaches the colon, and this has been shown to occur. ${ }^{13-15}$ Published data are too limited to be sure that premature dissolution in the small intestine does not happen in some patients - for example, in those with slow transit, or high small intestinal $\mathrm{pH}$. This is important not only because it would limit therapeutic efficacy, but also because mesalazine is potentially nephrotoxic. ${ }^{10}$ Peak

Table Synonyms

\begin{tabular}{lll}
\hline Chemical name & Generic name & Trade name(s) \\
\hline 15 aminosalicylic acid (5ASA) & Mesalazine & Asacol, Claversal, Pentasa, Salofalk \\
2 Azodisalicylate (ADS) & Olsalazine & Dipentum \\
3 Carboxyethyl-carbamoylphenol azosalicylate & Balsalazide & $?$ \\
$4\left\{\begin{array}{l}\text { 4 aminosalicylic acid (4ASA) } \\
\text { para aminosalicylic acid (PAS) }\end{array}\right.$ & - & - \\
\hline
\end{tabular}


serum concentrations of 5 amino salicylic acid after single doses of polymer coated mesalazine have been higher than after sulphasalazine,,$^{1+15}$ although accumulation does not seem to occur with more prolonged dosing. ${ }^{15}$

The second approach, that of using an alternative carrier to sulphapyridine, is illustrated by azodisalicylate (olsalazine, Dipentum), where two molecules of mesalazine have been joined together by a diazo bond, so that they each act as a carrier for the other. This drug too achieves high concentrations of free mesalazine in the faeces ${ }^{16}{ }^{18}$ but here a different problem has arisen. About $6 \%$ of patients experience drug induced diarrhoea ${ }^{19}$ caused by a secretory action of unsplit olsalazine in the small intestine..$^{20}$

\section{Are higher doses more effective?}

The new salicylates are thus effective agents for the treatment of relapse and maintenance of remission. Some trials have used doses which probably deliver more mesalazine ${ }^{821}$ to the colon than comparative doses of sulphasalazine, but here it is unclear whether greater therapeutic potency results. In one maintenance study $22 \%$ of patients relapsed over six months when taking $2.7 \mathrm{~g}$ of mesalazine as Asacol, compared with $20 \%$ of those taking $0.9 \mathrm{~g}$ of mesalazine in sulphasalazine. This was a disappointing result, as earlier studies had shown that the response to sulphasalazine was dose dependent. ${ }^{22}$ In another study of treatment of relapse Asacol, giving daily doses of mesalazine $0.8 \mathrm{~g}$ and $2.4 \mathrm{~g}$, and sulphasalazine giving daily doses of $0.84 \mathrm{~g}$, were compared. Significantly more patients taking high dose Asacol had sigmoidoscopic improvement, compared with sulphasalazine. In this study there were no significant dose dependent differences for mesalazine and there were trends suggesting that patients on low dose Asacol were doing better than those taking sulphasalazine. ${ }^{22}$ Similarly a recent report found patients taking olsalazine $2 \mathrm{~g}$ /day ( $2 \mathrm{~g}$ mesalazine) for relapse had less bleeding than those taking sulphasalazine $3 \mathrm{~g} /$ day $(1.1 \mathrm{~g}$ mesalazine), although sulphasalazine performed better if other variables such as the number of unformed stools were considered. ${ }^{23}$

The answers to two interesting questions thus remain unclear. Pharmacologically it remains possible that sulphasalazine possesses intrinsic activity, in addition to that résiding in mesalazine. ${ }^{24}$ Clinically it is not clear how high the dose can be safely pushed with these two agents and whether better treatment would then result. Conceivably there is more scope for such megadose therapy with one of the other agents such as balsalazide, in which mesalazine is linked to the poorly absorbed carrier, 4 aminobenzoyl-balanine. ${ }^{25}$ This drug has clinical efficacy similar to sulphasalazine when given at similar dosage, but with significantly fewer side effects. ${ }^{26}$ On one measure (change in haemoglobin) there were suggestions that it might be superior, but such observations need confirmation. On the limited data so far available, balsalazide has a therapeutic index which might allow delivery of much higher doses of mesalazine with an acceptable incidence of side effects.

Even if these alternatives to sulphasalazine have not been major therapeutic advances for most patients with ulcerative colitis, they have been a welcome addition for the large minority who are unable to tolerate sulphasalazine. In such patients polymer coated mesalazine and olsalazine are effective acute and maintenance treatments, although the rate of withdrawals because of intolerance (between 13 and $15 \%$ ) is higher than in 
unselected patients. ${ }^{27}$ The newer salicylates are also an advance in the sense that they lack sulphasalazine's ability to cause sulphapyridine mediated infertility. ${ }^{28-30}$

\section{CORTICOSTEROIDS}

These remain the main acute treatment, but their use is limited by side effects which make them unsuitable for maintenance. Orally active corticosteroids with purely topical activity, or with first pass metabolism so effective that no drug reaches the systemic circulation would be a major advance for two reasons. First, substantial increases in dose which this would allow might improve the effectiveness of corticosteroids in the treatment of relapse. Second, it would also be possible to re-explore a role for these drugs in the maintenance of remission. Results with the poorly absorbed preparations, beclomethasone, budesonide and tixocortol pivolate have shown that such drugs are undoubtedly active topical agents for distal disease. ${ }^{31-33}$ This is an encouraging, but so far limited application.

\section{AZATHIOPRINE}

Despite inconsistencies in the data, many gastroenterologists accept that azathioprine has therapeutic value in Crohn's disease, acting as a 'steroid sparing agent', though this only means that steroid sparing was used as an end point in trials to show therapeutic efficacy; it would be almost equally logical to describe corticosteroids as azathioprine-sparing agents.

The position is much less clear in ulcerative colitis. In the largest trial of azathioprine, 80 patients in relapse were randomised to supplemental azathioprine, or placebo and followed for 12 months. ${ }^{34}$ By this time 16 patients on azathioprine and nine patients on placebo had no further relapses: no significant difference. Nevertheless, we are among those who perceive azathioprine, or 6 mercaptopurine as useful for patients with poorly controlled ulcerative colitis. The design of most trials has not been ideal for showing benefit. Although the mode of action of azathioprine is not clear, most of its immunological effects occur with considerable latency, so that maximum benefit cannot be expected for at least a month. A controlled trial of azathioprine withdrawal from patients in established remission on the drug is needed. If azathioprine proved effective in patients with chronic continuous disease who were dependent on corticosteroids, this would be an important advance, as such patients often progress to colectomy.

\section{Topical treatments}

\section{SALICYLATES}

Topical mesalazine is an effective treatment for proctosigmoiditis. In mild and moderate disease, Campieri and colleagues ${ }^{35}$ showed that a $4 \mathrm{~g}$ dose was more effective than hydrocortisone enemas, with clinical and sigmoidoscopic improvement in $93 \%$ of patients. Likewise, the Danish 5ASA group showed that lower doses were at least as effective as prednisolone enemas. ${ }^{36}$ Initial problems with stability in solution have now been overcome. 4 Aminosalicylic acid (which is but para aminosalicylic acid, renamed for intrarectal use by gastroenterologists) may be preferable as a cheaper and more stable preparation and is probably equally effective, ${ }^{37}$ though the choice of an optimal agent has not been fully resolved. 
Topical treatment with high dose $(4 \mathrm{~g})$ mesalazine also works well in distal colitis refractory to conventional treatment. ${ }^{38}{ }^{39}$ In the latter study treatment for two months resulted in a $25 \%$ rate of local side effects with irritation, anal fissures and one abscess, though this has not been a problem in other trials.

How topical salicylates work and whether the mechanism is the same as when salicylates are used orally, producing lower local concentrations, is not known. Perhaps their ability to irritate, by a predominantly physical mechanism is important, because mild irritants, sodium salicylate and sulphasalazine itself have all been shown to be (cyto)protective to other parts of the gut. ${ }^{40-42}$

Although topical salicylates are not widely used they are an important advance for a subgroup of patients with poorly responsive chronic proctitis.

TOPICAL STEROIDS - COSMETIC ADVANTAGES OF FOAMS

There is now little doubt that steroid foams are effective and they are widely used. They appear to be as effective as enemas, but the comparative trials have been relatively small. They are much preferred by patients, largely on the grounds of convenience and acceptability. ${ }^{43}$ This suggests that development of a foam preparation of one of the salicylates for topical use would lead to more widespread adoption of these agents, which can be therapeutically superior to topical corticosteroids.

\section{Synopsis}

Recently, oenological prejudices were challenged by the use of a points scoring system (from 50 to 100) to evaluate wine in a book now widely regarded as one of the most authoritative. ${ }^{44}$ On this scale, a 1981 Chateau Citran described as 'emaciated' scored 65, a 1983 Chateau Kirwan scored 85, and a 1982 Petrus 100 . If the same approach were used for drugs used in ulcerative colitis to quantify an advance over conditions existing at the time of its introduction how would they score? Because they were the first available drugs in their class and clearly constituted major advances, corticosteroids and sulphasalazine both score 95 , the score being limited by a high level of side effects. The new salicylates score 75 , because they extend the benefits of sulphasalazine to a minority of patients but they have the potential to score 90 if increased dosing and greater effectiveness over sulphasalazine can be achieved. Salicylate enemas score 80 , because they advance treatment over topical corticosteroids for patients with resistant distal disease, but the mode of delivery needs improvement. Steroid foams also score 80, particularly if the patient's vote is taken into account. Azathioprine's score cannot be calculated because there is doubt over its efficacy, but it is potentially 88 if it saves patients with difficult disease from colectomy. We can only guess what an oral non-absorbed steroid would score, but if response rates for relapse were substantially improved, or if corticosteroids could be used as effective maintenance treatment, it could be as high as 95 . There are indications that we should 'watch this space'.

Department of Therapeutics,

University Hospital, Nottingham NG7 $2 \mathrm{UH}$ 


\section{References}

1 Svartz N. The treatment of 124 cases of ulcerative colitis with salazopyrin and attempts of desensibilisation in cases of hypersensitiveness to sulfa. Acta Med Scand 1948; 206: 465-72.

2 Truelove SC, Witts LJ. Cortisone in ulcerative colitis. Br Med J 1955; ii: 1041-8.

3 Misiewicz JJ, Lennard-Jones JE, Cornell AM, Baron JH, Avery Jones F. Controlled trial of sulphasalazine in maintenance therapy for ulcerative colitis. Lancet 1962; i: 185-8.

4 Dissanayake AS, Truelove SC. A controlled therapeutic trial of long-term maintenance treatment of ulcerative colitis with sulphasalazine (Salazopyrine). Gut 1973; 14: 923-6.

5 Azad Khan AK, Piris J, Truelove SC. An experiment to determine the active therapeutic moiety of sulphasalazine. Lancet 1977; ii: 892-5.

6 Hees PAM van, Bakker JH, Tongeren JHM van. Effect of sulphapyridine, 5-aminosalicylic acid and placebo in patients with idiopathic proctitis: a study to determine the active therapeutic moiety of sulphasalazine. Gut 1980; 21: 532-635.

7 Dew MJ, Hughes P, Harries AD, Williams G, Evans BK, Rhodes J. Maintenance of remission in ulcerative colitis with oral preparation of 5-aminosalicylic acid. $\mathrm{Br} \mathrm{Med} \mathrm{J} \mathrm{1982;}$ 285: 1012 .

8 Dew MJ, Harries AD, Evans N, Evans BK, Rhodes J. Maintenance of remission in ulcerative colitis with 5-aminosalicylic acid in high dose by mouth. Br Med J 1983; 287: 23-4.

9 Donald IP. Wilkinson SP. The value of 5-aminosalicylic acid in inflammatory bowel disease for patients intolerant or allergic to sulphasalazine. Postgrad Med J 1985; 61: 1047-8.

10 Sandberg-Gertzen H, Jarnerot GJ, Kraaz W. Azodisal sodium in the treatment of ulcerative colitis. Gastroenterology 1986; 90: 1024-30.

11 Ireland A, Mason $\mathrm{CH}$, Jewell DP. Controlled trial comparing olsalazine and sulphasalazine for the maintenance treatment of ulcerative colitis. Gut 1988; 29: 835-7.

12 Meyers S, Sachar DB, Present DH, Janowitz HD. Olsalazine sodium in the treatment of ulcerative colitis among patients intolerant of sulphasalazine. Gastroenterology 1987; 93: 1255-62.

13 Dew MJ, Ryder REJ, Evans M, Evans BK, Rhodes J. Colonic release of 5-aminosalicylic acid from an oral preparation in active ulcerative colitis. Br J Clin Pharmacol 1983; 16: 185-7.

14 Dew MJ, Ebden P, Kidwai NS, Lee G, Evans BK, Rhodes J. Comparison of the absorption and metabolism of sulphasalazine and acrylic-coated 5-aminosalicylic acid in normal subjects and patients with colitis. Br J Clin Pharmacol 1984; 17: 474-6.

15 Mardini HA, Lindsay DC, Deighton CM, Record CO. Effect of polymer coating on faecal recovery of ingested 5-aminosalicylic acid in patients with ulcerative colitis. Gut 1987; 28: 1084-9.

16 Calder IC, Funder CC, Green CR, Ham KN, Tange JD. Nephrotoxic lesions from 5-aminosalicylic acid. Br J Med 1972; i: 152-4.

17 Willoughby CP, Aronsson JK, Agback H, Boin NO, Truelove SC. Distribution and metabolism in healthy volunteers of disodium azodisalicylate, a potential therapeutic agent for ulcerative colitis. Gut 1982; 23: 1081-7.

18 Lauritsen K, Hansen J, Ryde M, Rask-Madsen J. Colonic azodisalicylate metabolism determined by in vivo dialysis in healthy volunteers and patients with ulcerative colitis. Gastroenterology 1984; 86: 1496-500.

19 G Jarnerot. Clinical tolerance of olsalazine. Paper delivered at Oxford meeting on Olsalazine. 1987.

20 Mohsen AQM, Mulvey D, Priddle JD, Parsons DS, Jewell DP. Effects of olsalazine in the jejunum of the rat. Gut 1987; 28: 346-52.

21 Rao SSC, 'Holdsworth CD, Palmer KL, Cann PA, Dundas SA, Corbett CL. Olsalazine versus sulphasalazine (SASP) in first attacks of ulcerative colitis (UC): a double blind study [Abstract]. Gut 1988; 29: A705-6.

22 Azad Khan AK, Howes DT, Piris J, Truelove SC. Optimum dose of sulphasalazine for maintenance treatment in ulcerative colitis. Gut 1980; 21: 232-40.

23 Riley SA, Mani V, Goodman MJ, Herd ME, Dutt S, Turnberg LA. Comparison of delayed release 5-aminosalicylic acid (mesalazine) and sulphasalazine in the treatment of mild to moderate ulcerative colitis relapse. Gut 1988; 29: 669-74.

24 Anonymous. Sulphasalazine: drug or prodrug? [Editorial]. Lancet 1987; i: 1299-300.

25 Chan RP, Pope DJ, Gilbert AP, Sacra PJ, Baron JH, Lennard-Jones JE. Studies of two novel sulphasalazine analogs, ipsalazide and balsalazide. Dig. Dis Sci 1983; 28: 609-15.

26 McIntyre PB, Rodrigues CA, Lennard-Jones J, et al. Balsalazide in the maintenance treatment of patients with ulcerative colitis, a double-blind comparison with sulphasalazine. Aliment Pharmacol Ther 1988; 2: 237-43. 
27 Jarnerot G. New 5-aminosalicylic acid based drugs: An evaluation of properties and possible role in the treatment of inflammatory bowel disease. In: Jarnerot G, ed. Inflammatory bowel disease. New York: Raven Press, 1987: 153-4.

28 Birnie GG, McLeod TIF, Watkinson G. Incidence of sulphasalazine-induced male infertility. Gut 1981; 22: 452-5.

29 O'Morain C, Smethurst P, Dore CJ. Reversible male infertility due to sulphasalazine: studies in man and rat. Gut $1984 ; 25: 1078-84$.

30 Riley SA, Lecarpentier J, Mani V, Goodman MJ, Mandal BK, Turnberg LA. Sulphasalazine induced seminal abnormalities in ulcerative colitis: results of mesalazine substitution. Gut 1987; 28: 1008-12.

31 Kumana CR, Seaton T, Meghji M, Castelli M. Beclomethasone dipropionate enemas for treating inflammatory bowel disease without producing Cushing's syndrome or hypothalamic pituitary adrenal suppression. Lancet 1982; i: 579-83.

32 Danielsson A, Hellors G, Lyrenas E, Lofberg R, Nilsson A, et al. A controlled randomised trial of budesonide versus prednisolone retention enemas in active distal ulcerative colitis. Scand J Gastroenterol 1987; 22: 987-92.

33 Hanauer SB, Kirsner JB, Barrett WE. The treatment of left sided colitis with tixocortol pivalate. Gastroenterology 1986; 90: 1449.

34 Jewell DP, Truelove SC. Azathioprine in ulcerative colitis: final report on controlled therapeutic trial. Br Med J 1974; iv: 627-30.

35 Campieri M, Lanfranchi GA, Bazzocchi G, et al. Treatment of ulcerative volitis with highdose 5-aminosalicylic acid enemas. Lancet 1981; ii: 270-1.

36 Bondesen S, and a Danish 5-ASA Study Group. Topical 5-aminosalicylic acid (5-ASA) versus prednisolone in ulcerative proctosigmoiditis [Abstract]. Scand J Gastroenterol 1986; [suppl 120], 21: 6.

37 Campieri M, Lanfranchi GA, Bertoni, F, et al. A double-blind clinical trial to compare the effects of 4-aminosalicylic acid to 5-aminosalicylic acid in topical treatment of ulcerative colitis. Digestion 1984; 29: 204-8.

38 Guarino S, Chatzinoff M, Berk T, Friedman LS. 5-Aminosalicylic acid enemas in refractory distal ulcerative colitis. Am J Gastroenterol 1987; 82: 732.

39 McPhee MS, Swan ST, Biddle WL, Greenberger NS. Proctocolitis unresponsive to conventional therapy: Response to 5-aminosalicylic acid enemas. Dig Dis Sci 1987; [suppl 32]: 76-81.

40 Robert A. Gastric cytoprotection by sodium salicylate. Prostaglandins 1981; 21 [suppl]: 139-45.

41 Hawkey CJ, Rampton DS. Evidence that adaptive cytoprotection in rats is not mediated by prostaglandins. Gastroenterology 1988; 94: 948-54.

42 Cho CH, Ogle CW, Sevilla EL. The protective effects of sulphasalazine against ethanolinduced gastric damage in rats. Br J Pharmacol 1987; 92: 31-7.

43 Somerville KW, Langman MJS, Kane SP, MacGilchrist AJ, Watkinson G, Salmon P. Effect of treatment of symptoms and quality of life in patients with ulcerative colitis: a comparative trial of hydrocortisone acetate foam and prednisolsone 21-phosphate enemas. Br Med J 1985; 291: 866-7.

44 Parker R. The wine buyers guide, London: Darling Kindersley, 1987. 